\title{
Developing career management skills within a flipped course in Managerial Communication
}

\section{Johnstone, Bruce Alexander}

Bachelor of International Business Program, Monash University, Australia.

\begin{abstract}
This paper reports on research in progress to evaluate the effectiveness of strategies for developing career management skills (the processes involved in obtaining and maintaining work) in undergraduate university business students in Melbourne, Australia. These strategies are incorporated into a course in Managerial Communication - taught using blended-learning and a flipped-classroom approach. The course's active learning workshops provide opportunities to rehearse the process of undertaking a job search, creating application documents and being interviewed. Students are also prepared for modern recruiting processes by going through an online video interview simulation and preparing an online Linkedin profile. Finally, the design of the workshops and the terminology and approach to project-based learning prepares students for workplaces that employ Agile methodology.
\end{abstract}

Keywords: career skills, career management, employability, resumes, video interviews, Linkedin profiles, Agile workplaces 


\section{Introduction}

University educators in Australia (in common with the United Kingdom and Canada) are increasing challenged to improve the career outcomes of their graduates. This has brought a greater emphasis on developing skills that employers value (Ravenscroft \& Luhanga 2014).

While workplace skills are important for graduates who have moved into employment, it has become increasingly recognised that we cannot take for granted that graduates possess the skills necessary to secure the employment in which to demonstrate these skills (McKeown \& Lindorff, 2011). The group of skills referred to as career management skills can be defined as the processes involved in obtaining and maintaining work (Bridgstock, 2009). These job securing skills are clearly important in improving graduate outcomes (Jackson \& Wilton, 2016) and encompass the ability to self-assess and engage in personal development for opportunities in the job market, to carry out a job search and undergo a recruitment selection process.

This paper reports on research in progress to assess the effectiveness of strategies for developing career management skills in undergraduate university students in Melbourne Australia. These strategies are incorporated into a course in Managerial Communication taught using blended-learning and a flipped-classroom approach. The course's active learning workshops provide opportunities to rehearse the process of undertaking a job search, creating application documents and being interviewed. Students are also prepared for modern recruiting processes by going through an online video interview simulation and preparing an online profile on the professional networking platform Linkedin.com. Finally, the design of the workshops and the terminology and Agile approach to project-based learning (Lang, 2017) prepares students for workplaces that employ Agile methodology (Denning, 2016).

\section{Background}

The Monash University Bachelor of International Business (BIB) program was launched in 2015 in newly refurbished and equipped premises in the Central Business District of Melbourne, Australia. From its inception the program incorporated new approaches to undergraduate teaching, including a flipped-classroom and blended learning approach to all courses. After working through online material, students participate in active learning workshops that use problem-based and team-based learning. The BIB also operates a trimester system that allows students to complete their undergraduate degree in two years and offers opportunities for international study and work experience placements. The BIB also sets out to include contact with employer organisations and professional practitioners with a program of industry guest speakers. 
The design of the BIB program creates two challenges for graduate employment. While the BIB operates on a trimester system, the opportunities for graduate recruitment and internships established by the university are naturally aligned with the semester timetable used by the large Monash campus at Caulfield and Clayton. The career services provided by the university are also located for the much larger student populations at Caulfield and Clayton. Hence, strategies to develop employability and career management skills that are woven into a course are of particular importance to the BIB program.

The course in Managerial Communication is taught at Monash Business School under the leadership of Nathan Eva. The author worked with Dr Eva to adapt the material for blended learning and flipped classroom delivery in 2015 and has coordinated and facilitated the course within the BIB, with the support of Dr Eva as Chief Examiner. This work included creating online lessons for all topics and teaching innovations to develop skills in creating online profiles and undertaking online video interviews.

The Managerial Communication course includes coverage of communication theory, personality testing, self assessment, writing letters and resumes, interview skills, providing feedback, decision-making, public speaking and presentation skills, group problem-solving and proposal writing and digital communications. The following is a summary of how strategies for developing career management skills are incorporated into the course.

\section{Personality testing, self assessment and creating a development plan}

Early in the trimester students undertake a range of personality tests including Myers Briggs Type Indicator (MBTI), the Big Five, Social Styles and Emotional Intelligence (EI). Readings and online lessons provide insights into understanding the results of these texts and the implications of different personality types in the workplace. Students are then challenged to research further and write a self-assessment essay in which they describe their personality and explain the implications for their careers. The essay must include strategies to build on their strengths and develop themselves in ways that will strengthen perceived weaknesses. The self-assessment essay is an assessment weighted at 30 percent of the course grade. Formative feedback is delivered after the marking process through an individual conversation with the facilitator.

\section{Job searching and creating application documents}

Each week of the course a new topic and its associated online package is released in the Moodle Virtual Learning Environment (VLE). The online packages include interactive audio-video lessons, readings, videos and an online quiz that can be answered after completing the lessons and readings. The quiz has a closing date and time set to ensure it is completed prior to the first workshop for that week. 
Resumes and Cover Letters is one such week topic. Students complete online lessons in preparing resumes and cover letters (prepared with input from the Monash Careers Service), a selection of readings on the subject and a quiz. The assessment for this topic is to locate a job opportunity, and create a cover letter and resume to suit that opportunity.

Students are provided required to conduct an online search and find a real listing for a job they would personally be interested in on graduation (a model job description is provided as an alternative). Students must then create a resume and cover letter for themselves as if they wished to apply for the job opportunity selected. This work is then assessed by a moderated peer-marking process. All resumes and cover letters are marked by at least two other students who complete marking and feedback forms that measure the extent to which the documents match the best practice guidelines set out in the online lessons.

Students who are reluctant to expose their resumes to others, are permitted to use a pseudonym, only known to the facilitator. The facilitator moderates the results of the peer marking process and awards a mark. The resume and cover letter assessment is weighed at $8 \%$ of the course and it is explained to students that similar documents will have to be produced when they come to apply for graduate jobs, and this assessment has prepared them to be able to create high quality application documents.

Students are encouraged to think critically about weaknesses in their resume and how these could be strengthened. For example, students with no work experience of any kind can consider undertaking volunteering or work experience activities that can be added to their resumes. Others might join professional organisations that match their employment aspirations.

\section{Obtaining professional portraits for online use}

Students are advised not to include a photograph in their resume, unless they are applying for work as a model or actor. Employers are conscious that a photograph attached to a resume may give rise to discrimination based on conscious or unconscious predjudices based on age, gender or race. Some employers automatically rule out applicants who provide a photograph to avoid any suggestion of discrimination. Students are advised that their resumes should focus on skills and experience with the aim of securing an interview.

However, students still need a professional portrait of themselves to use on their online profile, as employers will often search online to review a candidate's profiles on professional networking sites such as Linkedin.com.

For this reason, having a professional portrait photograph taken is a workshop activity in Managerial Communication. Students are asked to arrive in professional attire and their photograph is taken by a photographer who is a member of the Monash eLearning team. 


\section{Creating online profiles for networking}

Creating an online profile on the professional networking site Linkedin.com is a workshop activity with a low stakes (two percent) assessment. The profile is required to match the student's resume and include education, experience and a personal statement. Students are also encouraged to consider using the Linkedin.com platform to begin professional networking, although there is no requirement for the profile to actually be posted publicly and they can have whatever privacy settings they wish. Students export a pdf copy of their Linkedin profile and submit that document for assessment.

Discussing an online profile is an opportunity to remind students that potential employers may search for information about them online, and they should manage their online image accordingly.

\section{Role playing panel interviews to rehearse skills}

Developing interview skills follows on from the process of searching and applying for a job and is a topic that occupies a week within the Managerial Communication course. The online package takes the standard approach of providing online lessons (for this topic based on material from the Monash Careers Service), readings and an online quiz that must be completed before the workshops.

The workshops for Interview Skills use structured role playing of panel interviews to provide students with experience in both interviewing and being interviewed. Students pose appropriate behavioral questions and practice answering them. They are also given the opportunity to practice providing answers to different types of aptitude tests employers may use to screen applicants.

\section{Online interview simulations using Vieple.com}

Online interviewing has been widely adopted by Australian corporations seeking to streamline their processes for selecting the most suitable job applicants, and BIB students will almost certainly find themselves taking online interviews when they begin to apply for graduate jobs. By developing the skills and confidence of our students to take these online interviews, we are providing them with a valuable edge in the highly competitive graduate job market and improving their career outcomes.

Monash College (a wholly-owned subsidiary of Monash University) opened an account on the Vieple.com platform in August 2016 and makes use of it in recruiting for its student internship programs. Since then the author has also been able to use this account to provide an online interview simulation as a workshop activity for the Managerial Communication course. 
The simulation initially allows students to take a quick test question to familiarise themselves with the process, this is a standard feature in Vieple. The simulation interview then asks four questions as follows:

\section{What are your three greatest strengths?}

2. Describe a team project you have been involved in. Who were the team members? What role did you take? What were the results?

3. Tell me about a situation in which you have had to adjust and adapt to change.

4. Describe a recent work or study-related problem. Tell me about the action you took to solve the problem. What was the outcome?

Students are given two minutes to answer each question, chosen because they are typical of online interviews in the real world. The first question provides applicants the opportunity to sell themselves and questions two; three and four are behavioural questions that seek to understand how applicants would behave in a new role, based on how they report that they have behaved in the past.

To implement the simulation in a workshop, students are asked to attend with a laptop or tablet. Each student receives a unique login name. Students are encouraged to leave the room and find a well-lit and quiet location with a plain background. When interviews have been recorded, students are issued with a second login name that allows them to login in as an Assessor with access to only their own interview. Students then critically appraise their own interview performance and share and compare with another student. When all students have had the opportunity to participate, we arrange for the logins to be reset and the simulation interviews deleted for privacy and data security reasons.

We have found that students participate well in this activity, although some need to overcome an initial reluctance. They generally report that they feel much more confident about a real world online interview after doing the simulation and believe that they will "... be much better at it next time”.

Some students require minor technical support to use Vieple.com. Usually this involves helping them switch on their camera or microphone or enabling popups in their browser. Anyone using a simulation like this in a workshop would be wise to have a technical support person available to students.

The online interview is not an assessment, however it contributes to a mark given for participation in workshop activities, weighed at 20\% and spread over 20 workshops. Assessing workshop participation is important to incentivise attendance and participation, so that career management skills are rehearsed and developed by all students. 


\section{Agile methodology}

Agile Methodology is widely used in managing digital technology projects (Denning, 2016) and its techniques have been adopted to organise work at a number of Australian banks, corporates and professional service firms (Boyd, 2018). The Managerial Communication course uses an Agile approach that aims to accelerate learning of the material while also giving students an advantage when they apply for roles in contemporary Agile workplaces (Lang, 2017).

Students applying for roles within Agile workplaces will have the benefit of being already familiar with much of the terminology and the way in which people and their work is organised. For example the cohort studying the course is referred to as the Managerial Communication Tribe. The tribe is divide up to contains squads of four to five people with a diverse range of backgrounds and skills.

Squads are required to self-organise to accomplish learning tasks and projects, and to build and maintain trust and respect between members. Each squad becomes a Knowledge Centre for one of the topics covered by the course. This means they will not only study the online material along with the rest of the tribe, but they will also develop and deliver a learning activity that the tribe will undertake during a workshop. Each squad will have one week to complete its activity development project and will undertake a sprint to rapidly develop the activity as a minimum viable product.

Squads also use a series of weekly scrums and huddles to complete their final project. The first workshop each week includes a scrum meeting in which the course facilitator acts as a customer for learning projects assigned to the squads. Customers state their requirements and work closely with the squad. They must be provided with continual increments of progress about which they must provide feedback. However, customers may also introduce new requirements at the last minute, which squads must accept and complete.

Each squad appoints a scrum master who will assign tasks and monitor progress of task completion by individuals and the squad. Additional weekly workshops are termed huddles in which squads meet to co-work and complete tasks assigned in scrums. Students understand that the Agile approach requires determined work until the task is complete.

\section{Research in progress}

Students at Monash University are surveyed on their experience using the Student Evaluation of Teaching and Units (SETU) and the results show high levels of satisfaction for the teaching of Managerial Communication. Students also provide the facilitator with unsolicited feedback and comments, for example that the course “... was likely to be the one which has the most positive impact on my future career". 
The author is currently developing, and seeking ethics approval for, a survey that will follow a 2018 cohort of Managerial Communication course students as they attempt to enter the workforce. Students, who agree to participate, will be e-mailed links to an online survey at the completion of the course and a series of further questionnaires over the postgraduation period.

This research will cover the employment outcomes achieved by the cohort, which can be compared to graduate outcomes for other students. The survey will also establish the type of employment the students have, and the extent to which the students' employment aspirations were met. Finally the survey will ask students to rate the value and usefulness of the career management activities included in Managerial Communication.

The results of the proposed survey will assess the value of the course and guide the development of future approaches to developing career management skills.

\section{References}

Boyd, Tony (2018, 3 January) Business gets the agile bug - AFR Digital Editions. www.afr.com

Bridgstock, Ruth (2009) The graduate attributes we've overlooked: enhancing graduate employability through career management skills, Higher Education Research \& Development, 28:1, 31-44, DOI: 10.1080/07294360802444347

Denning, S. (2016). How to make the whole organization "agile". Strategy \& Leadership, 44(4), 10-17.

Jackson, D \& Wilton, N (2016) Developing career management competencies among undergraduates and the role of work-integrated learning, Teaching in Higher Education, 21:3, 266-286, DOI: 10.1080/13562517.2015.1136281

Lang, G. (2017). Agile learning: Sprinting through the semester. Information Systems Education Journal, 15(3), 14-21.

McKeown, T., \& Lindorff, M. (2011). The graduate job search process--A lesson in persistence rather than good career management? Education \& Training, 53(4), 310320.

Ravenscroft, Brenda \& Luhanga, Ulemu. (2014). Developing Employability skills in Humanities and Social Sciences using the Flipped Model. Proceedings of the International Conference on e-Learning, ICEL. 142-149. 